\title{
Changes in the forearm associated with median nerve compression at the wrist in the guinea-pig
}

\author{
MARGARET H. ANDERSON ${ }^{1}$, PAMELA M. FULLERTON ${ }^{2}$, R. W. Gilliatt, \\ AND J. E. C. HERN
}

From the Institute of Neurology, Queen Square, London

The spontaneous compression of the median nerve at the wrist which occurs in guinea-pigs provides a useful model for the study of problems connected with chronic nerve compression. Previous work (Fullerton and Gilliatt, 1967) has suggested that the condition is rare in young guinea-pigs but that it occurs in a substantial proportion of animals aged 2 years or more. Nerve conduction studies can be used to screen batches of animals so that those with suitable lesions at the wrist can be picked out for further investigation.

The present paper is concerned with the retrograde changes which occur in the forearm when a severe compressive lesion is present at the wrist. It is hoped that the findings may throw some light on the changes which occur proximal to localized lesions of human peripheral nerves.

\section{MATERIAL AND METHODS}

Healthy male and female guinea-pigs were used, their ages ranging from 5 to $\mathbf{4 8}$ months. Approximately half of these had been bred in our own animal house; the remainder was supplied from Allington Farm, Porton Down, by the courtesy of Mr. J. S. Paterson.

As a standard screening procedure animals were anaesthetized, the ulnar nerve divided in the forearm, and the median nerve stimulated in the axilla, muscle action potentials being recorded from the small muscles of the fore-foot. The anaesthetic and the stimulating and recording electrodes were similar to those used previously (Fullerton and Gilliatt, 1967). Stimulation in the axilla had the advantage that maximal shocks could be delivered to the median nerve without any risk of current spread to the ulnar nerve below the level at which it had been divided in the forearm. At the wrist it was much more difficult to stimulate the median nerve without some spread of current to the ulnar nerve, and careful positioning of the cathode was necessary. This made the procedure more time consuming, and it increased the risk of trauma to the nerve. Stimulation in the axilla was therefore preferred as a routine procedure.

'Supported by a grant from the National Fund for Research into Crippling Diseases.

${ }^{2}$ Part-time member of Scientific Staff, M.R.C. Toxicology Unit, Carshalton, Surrey.
Fifty-three nerves from guinea-pigs aged 22 to $48 \overparen{\mathrm{D}}$ months and 28 nerves from guinea-pigs aged 5 to 12 months were examined. In the former group nerve $e^{\mathcal{S}}$ stimulation failed to elicit a muscle response in eight cases, $\vec{\circ}$ whereas a muscle response was obtained in all cases in the latter group. The results of latency measurement are $\vec{\omega}$ shown in Fig. 1. It can be seen that most of the guinea- pigs aged 5 to 12 months had latencies which were less than $3.0 \mathrm{msec}$, whereas more than half of the old animals? had latencies in excess of this figure. In those in which ${ }_{\omega}^{\omega}$ latency was substantially increased, the muscle responsewas sometimes reduced in amplitude, dispersed, and polyphasic. In two of the old animals only a single moter unit could be excited electrically, the latency being to을 $\mathrm{msec}$ in one case and $11.0 \mathrm{msec}$ in the other.

Nerves for histology were taken from animals with severe electrical abnormalities, those with milder changes being discarded. When normal nerves were required a 5 ( controls, these were taken from animals less than $12<$ months old and with normal electrical findings. In a feiv $\overrightarrow{0}$ cases histological material from animals used in outr previous study was re-examined.

After the electrophysiological recordings had been made, animals were killed and, in suitable cases, the median nerve below the elbow was removed and placed $\bar{\partial}$ on a card for fixation. In removing the specimen, care was taken to avoid excessive stretching as this is known to affect fibre diameter (Kashef, 1966). In some animals the $\bigcirc$ median nerve from the mid-forearm to the palm was $\overrightarrow{\vec{O}}$ removed in one piece, fixed in Flemming's solution and 3 embedded in paraffin. Transverse sections, $5 \mu$ thick, $?$ were then cut at 1,2 , or $5 \mathrm{~mm}$ intervals and stained for myelin by the modified Weigert method (Gutmann and Sanders, 1943). In others the nerve in the forearm was separated from the wrist portion so that one specimen? could be used for the preparation of single fibres and the other embedded in paraffin as described above. When single fibres were to be examined, nerves were fixed in $10 \%$ formol-saline and stained by $1 \%$ osmium tetroxide. They were then teased apart in glycerin as describedo previously (Fullerton and Gilliatt, 1967).

For the measurement of fibre numbers and fibre $\frac{D}{2}$ diameter, transverse sections were photographed, and prints prepared at a magnification of $\times 1,000$, the photo- $N$ graphy and counting technique being similar to that ${ }^{\circ}$ described by Swallow (1966). The calculation of fibre $N$ density followed the method described by Swallow, the N 


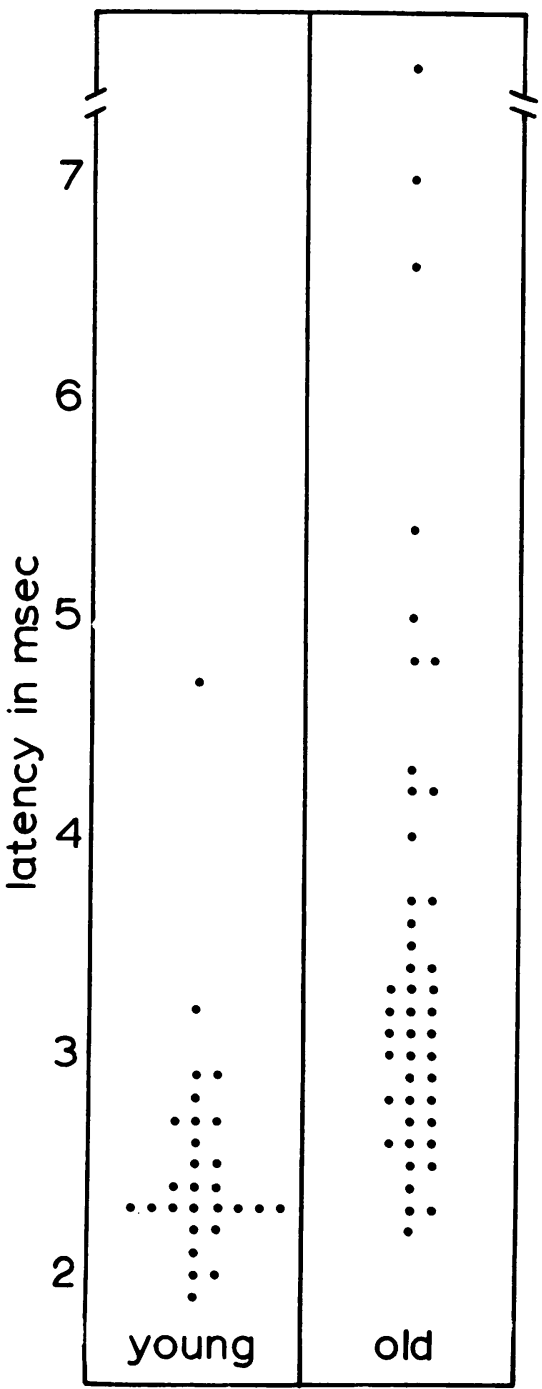

FIG. 1. Latency of muscle action potentials recorded from the forefoot after nerve stimulation in the axilla. Ulnar nerve previously cut in the forearm. Single value above break is $11.0 \mathrm{msec}$.

area of each fascicle being obtained from the diameter measured to the inner border of the perineurial sheath. Fascicles less than $50 \mu$ in diameter were not used as the method becomes unreliable with fascicles of this size.

In single fibres prepared from teased nerves, the diameter of individual internodal segments was measured with an oil-immersion lens at a magnification of $\times 1,000$, using a calibrated eyepiece. Since there can be considerable variation in diameter at different points along the same internode, a standard procedure was adopted in which the diameter was measured at $100 \mu$ intervals, no measurement being taken nearer than $50 \mu$ to a node of
Ranvier. The mean diameter of the internodal segment was then calculated from the six to nine readings which had been taken (their exact number depending upon the length of the segment).

\section{RESULTS}

Our previous work suggested that fibre density was reduced in transverse sections of the median nerve taken as high as $10 \mathrm{~mm}$ above the level of compression at the wrist. We have now examined the median nerve in the mid-forearm ( 15 to $20 \mathrm{~mm}$ above the wrist) in both affected and control animals, with the following results.

Transverse sections from two guinea-pigs aged 5 and 8 months were used as controls. No abnormality had been detected in sections taken at the level of the wrist; nerve conduction studies in these animals had also been normal. Fibre counts from sections in the mid-forearm are shown in Table 1, from which it can be seen that the total number of myelinated fibres in the median nerve was 2,634 in one case and 2,272 in the other. Of these, 40 to $50 \%$ were classified as large myelinated fibres on the basis of an external diameter of not less than $6 \mu$.

TABLE 1

NUMBERS OF MYELINATED FIBRES IN MEDIAN NERVE IN MID-FOREARM

\begin{tabular}{lccc}
\hline & $\begin{array}{c}\text { Diameter } \\
2 \text { to } 5 \mu \\
\text { (incl.) }\end{array}$ & $\begin{array}{c}\text { Diameter } \\
6 \mu \text { or } \\
\text { greater }\end{array}$ & Total \\
\hline Control & & & \\
$\quad$ Gp 156 & 1,574 & 1,060 & 2,634 \\
Gp 244 & 1,200 & 1,072 & 2,272 \\
Demyelination at wrist & 1,383 & 1,242 & 2,625 \\
$\quad$ Gp 182 & 1,064 & 506 & 1,570 \\
Degeneration at wrist & 1,130 & 611 & 1,741 \\
Gp 149 & & & \\
\hline
\end{tabular}

Fibre counts were also made on sections from the mid-forearm of an animal (Gp 182) in which compression at the wrist had produced local demyelination of the median nerve. Conduction studies had shown a delayed and dispersed muscle response to nerve stimulation. Details of the electrophysiological results and of the histological findings at the level of the wrist and below were described in our previous paper (see Figs. 2 and 8 of Fullerton and Gilliatt, 1967). The myelinated fibre content of the nerve in the mid-forearm is shown in Table 1 , and it can be seen that both the total number of fibres and the proportion of large fibres were similar to those of the control nerves. The fibre diameter histogram was also normal. It must therefore be concluded that if there is a retrograde change in 
fibre diameter proximal to the segmental demyelination caused by chronic compression, our technique has not been sufficiently sensitive to demonstrate it.

The findings in two animals (Gp 149 and 155) with complete degeneration of the median nerve at the wrist were very different. In both cases the muscle response to nerve stimulation was lost, and transverse sections showed no myelinated fibres in the median nerve at the level of the lesion or distal to it. The histological findings in one of these animals (Gp 155) were given in detail in our previous paper (see Figs. 9 and 10 of Fullerton and Gilliatt, 1967).

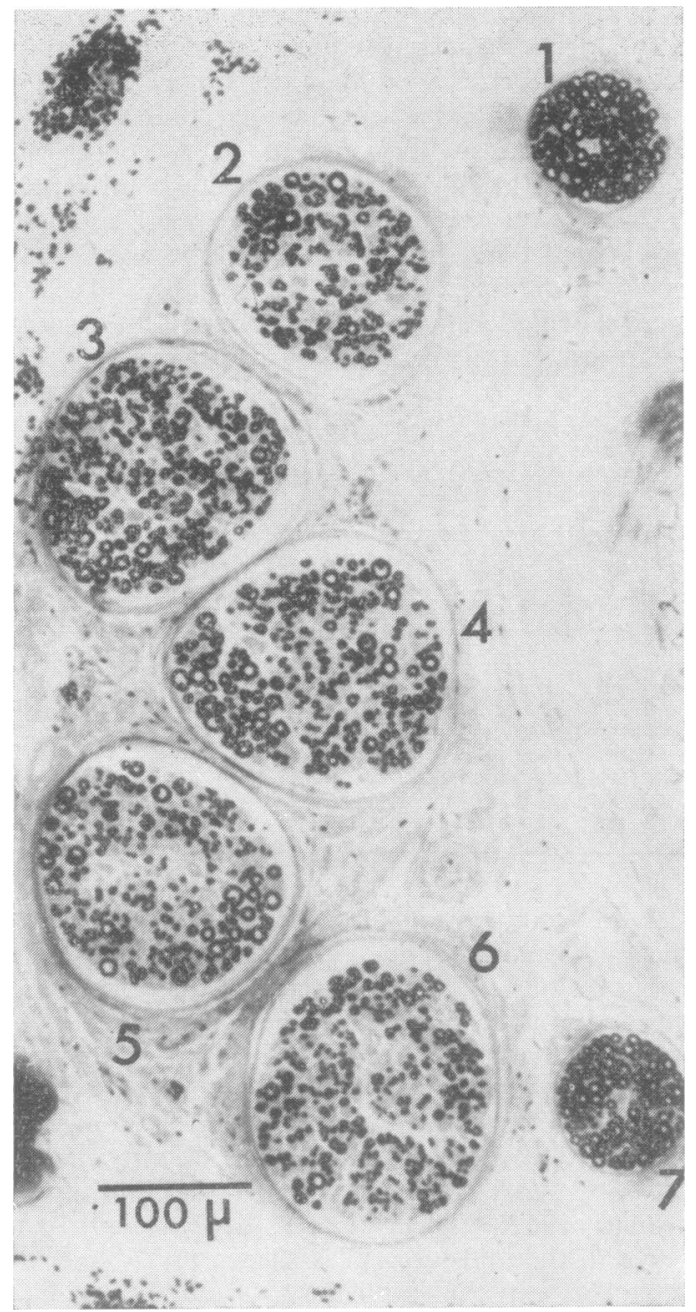

FIG. 2. Gp 149. Transverse section of the median nerve $20 \mathrm{~mm}$ above the wrist. Note two small fascicles (1 and 7) containing unaffected cutaneous afferents from the lower forearm. Modified Weigert stain.
From Table 1 it can be seen that in both Gp $149 \bar{Z}$

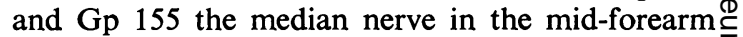
contained fewer myelinated fibres than the controlo nerves. This reduction was most marked for the large fibres which were reduced to approximately half the number found in the controls.

The true extent of the change was in fact greater than these figures suggest, since both of the affected nerves contained some myelinated cutaneous afferent fibres which had joined the main nerve trunk in the $\Rightarrow$ lower forearm and which were unaffected by the $\stackrel{?}{?}$ lesion at the wrist. At the mid-forearm level, some? of these unaffected fibres were still grouped in small superficial fascicles which could be easily recognized $\frac{\bar{\omega}}{\vec{D}}$ in transverse sections-for example, fascicles 1 and $\stackrel{\Phi}{\mathscr{D}}$ 7 of Fig. 2. Histograms of fibre aiameter for these $\frac{\omega}{\infty}$ two unaffected fascicles and for affected fascicles 2 to 6 are shown in Fig. 3. This confirms the reduction in fibre density in the affected fascicles (Fig. 3b) $\vec{\omega}$

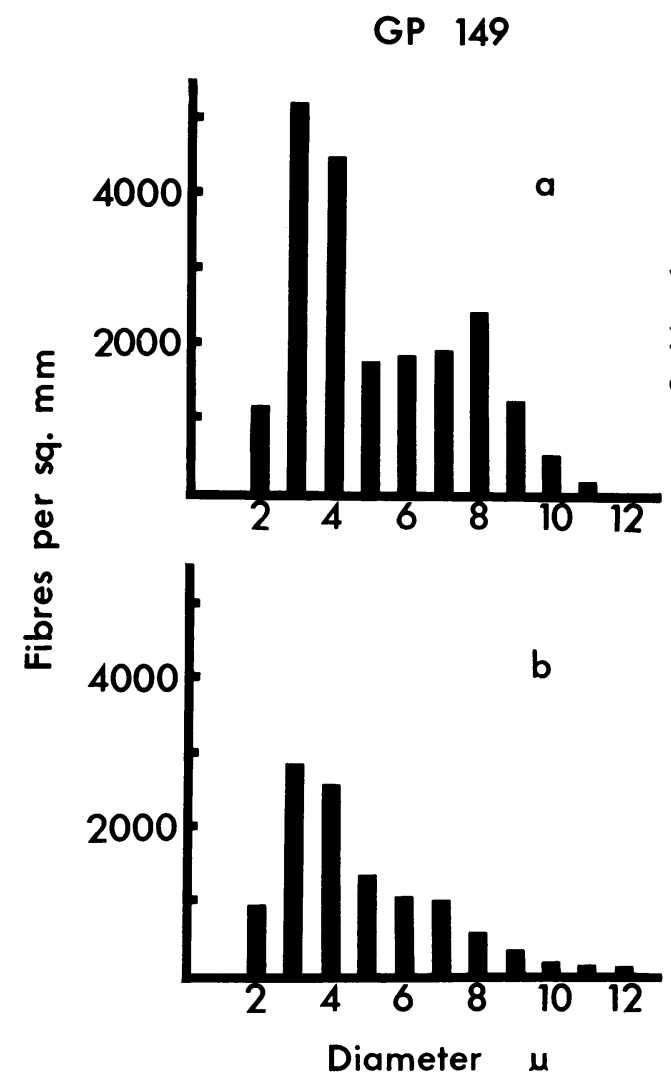

FIG. 3. Gp 149. Histograms of myelinated fibre densityñ obtained from the section shown in Fig. 2. Results for unaffected fascicles 1 and 7 shown in (a) those for affected $N$ fascicles 2 to 6 (inclusive) shown in (b). 
compared with the unaffected ones (Fig. 3a); it is clear that this reduction is mainly in the large fibre group, small fibre density being relatively well preserved.

Results for both Gp 149 and $\mathrm{Gp} 155$ are given in Table 2, from which it can be seen that the fibre density in the unaffected fascicles was similar to that of control nerves. This establishes the important point that the fibre loss in the affected fascicles was not due to a generalized process such as ageing, but was a true retrograde change in fibres which had undergone degeneration distally.

\section{TABLE 2}

DENSITY OF MYELINATED FIBRES IN MEDIAN NERVE IN MIDFOREARM EXPRESSED AS THOUSAND FIBRES PER SQ. MM

\begin{tabular}{lccc}
\hline & $\begin{array}{c}\text { Diameter } \\
2 \text { to } 5 \mu \\
\text { (incl.) }\end{array}$ & $\begin{array}{c}\text { Diameter } \\
6 \mu \text { or } \\
\text { greater }\end{array}$ & $\begin{array}{c}\text { All } \\
\text { fibres }\end{array}$ \\
\hline Affected fascicles & & & \\
Gp 149 & 7.8 & 3.4 & $11 \cdot 2$ \\
Gp 155 & 9.5 & 4.6 & 13.8 \\
Unaffected fascicles & 12.6 & $8 \cdot 1$ & 20.7 \\
Gp 149 & 14.0 & 10.3 & 24.3 \\
$\begin{array}{l}\text { Gp 155 } \\
\text { Whole nerves (controls) }\end{array}$ & 12.6 & 8.6 & 21.2 \\
Gp 156 & $9 \cdot 2$ & 8.3 & 17.5 \\
Gp 244 & & & \\
\hline
\end{tabular}

Figure 4 shows three fascicles from another section taken in the mid-forearm of $\mathrm{Gp} \mathrm{149.} \mathrm{Above}$ are two unaffected fascicles which were seen to leave the main nerve trunk in the lower forearm. Below is a fascicle which has been classified as 'affected'. However, it can be seen that it contains a group of large myelinated fibres lying close together near the perineurial sheath at six o'clock, which stand out clearly from the smaller fibres composing the rest of the fascicle. From our sections at lower levels it seemed probable that the large diameter fibres were unaffected ones from the lower forearm which had entered the fascicle a few millimetres distally. Without serial sections extending over several millimetres we could not be absolutely certain of this, but we concluded that even our 'affected' fascicles probably contained some fibres which had escaped distal compression. Without them the reduction in large fibre density would have been even greater than it appears to be in Table 2 .

There are several possible explanations for the apparent loss of large myelinated fibres in our transverse sections. In the first place, this might be due to genuine fitre loss - that is, retrograde degeneration affecting both axons and their myelin sheaths. Alternatively, some reduction of fibre diameter might have occurred without complete degeneration, although one would expect this to have produced an

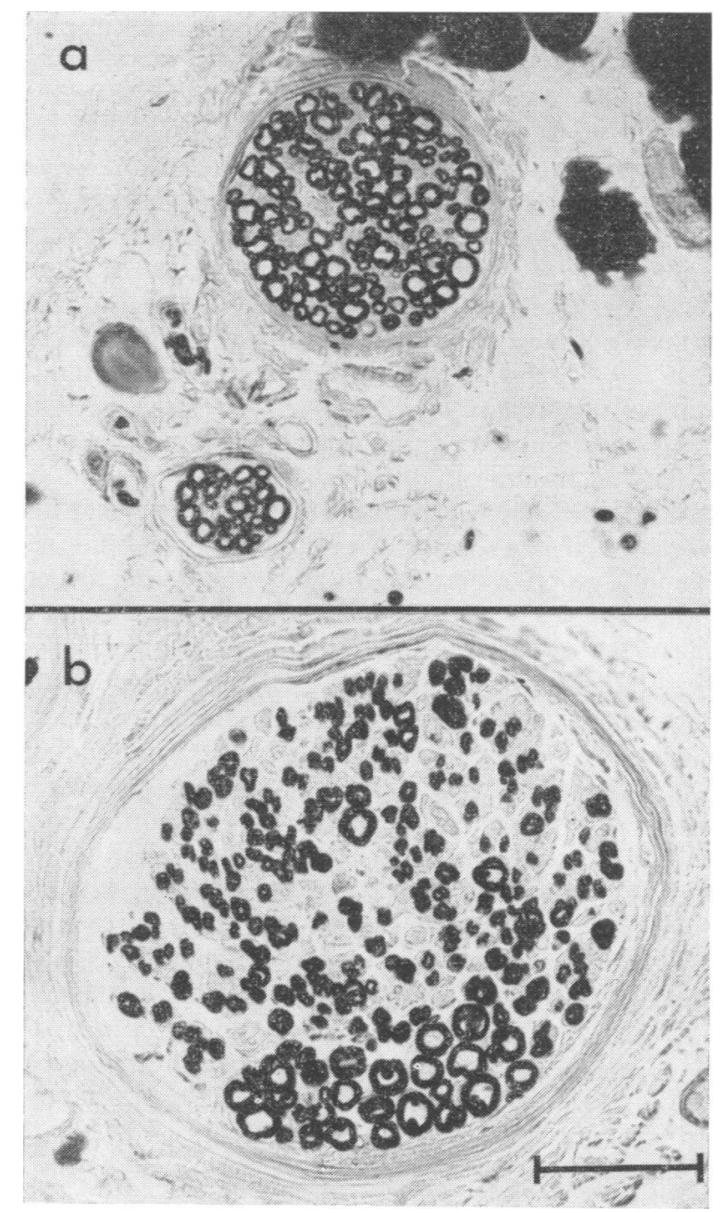

FIG. 4. Gp 149. Fascicles from another transverse section taken in the mid-forearm to show (a) two unaffected fascicles and (b) a fascicle classified as 'affected', although it contains a group of apparently unaffected fibres. Modified Weigert stain. Scale $50 \mu$.

increase in the number of small fibres to compensate for the apparent loss of large ones. In fact, Table 1 shows not an increase but a slight reduction in the number of small fibres in affected nerves. Finally, there is the possibility that segmental demyelination might be present in the forearm, since this process is known to occur immediately above the level of the lesion at the wrist (Fullerton and Gilliatt, 1967).

To investigate these possibilities further, the appearances of individual fibres were examined in teased preparations, with the following results.

In all our animals with severe lesions at the wrist, myelin debris was found among surviving fibres in the mid-forearm, suggesting that retrograde degeneration of some fibres was occurring at this level. 
The appearances were similar to those seen in fibres undergoing Wallerian degeneration; examples of different stages of degeneration in affected nerves are shown in Fig. 5.

There was little evidence of regeneration in our material. In one animal (Gp 252) a few fibres were found to have an internodal length which was inappropriately short in relation to fibre diameter. This was thought to indicate regeneration, but other severely affected nerves did not show this change, and so its relation to the lesion at the wrist must remain uncertain.

In addition to complete degeneration, demyelination was present in the forearm. This should not perhaps be called segmental demyelination as it only occasionally involved a complete internodal segment. The characteristic finding was demyelination extending for 150 to $250 \mu$ and situated at one end of an internodal segment; in many cases remyelination had occurred, resulting in a short 'intercalated' segment (Lubińska, 1958) with thin myelin but easily recognizable Schmidt-Lantermann clefts. Demyelination was commonly seen at successive nodes along the same fibre, and it was most often found immediately above the main lesion at the wrist (cf. Lubińska, 1961). The example shown in Fig. 6 was in fact from the mid-forearm, but the phenomenon was relatively rare at this level. Of a total of 221 fibres which were taken from the midforearm in seven animals with severe lesions at the wrist, only 19 showed paranodal demyelination or intercalated segments of the type described above, an incidence of less than $10 \%$. If only $10 \%$ of the fibres were affected, and if demyelination occupie only $20 \%$ of the lensth of each internode, one woul not expect the number of myelinated fibres in 9 transverse section to be reduced by more than $2 \%$ Thus the demyelination present at this level is clearly not sufficient to account for the marked loss of large myelinated fibres shown in Tables 1 and 2. Sligh widening of the nodal gap (up to $5 \mu$ ) was a more frequent finding but this is even less likely to affect myelinated fibre counts in transverse sections. It is discussed further below in relation to other morpho logical changes in the paranodal myelin.

To investigate possible reduction of fibre diametero 100 internodal segments were selected which had af internodal length of between 700 and $800 \mu ; 50$ o\$ these came from affected nerves and 50 were takef from control nerves. Their diameters were then measured and results for the two groups compared. Details of the animals used for this comparison arE shown in Table 3 . In all cases the fibres were take? from the mid-forearm. Those with paranodal des myelination or intercalated segments were excluded as, in these cases, we were uncertain where the original nodes of Ranvier had been.

The results of diameter measurement are showio in Fig. 7 and Table 4 from which it can be seen thag the mean diameter of the 50 internodal segments from the affected animals was only $6.9 \mu$ compage with $8.6 \mu$ for the controls. This is a highly signio ficant difference $(t=6.57 ; P<0.001)$, altholf the mean internodal length of the two groups ( $\& F$ and $744 \mu$ ) was almost identical.

It seemed unlikely that the reduction in diametes

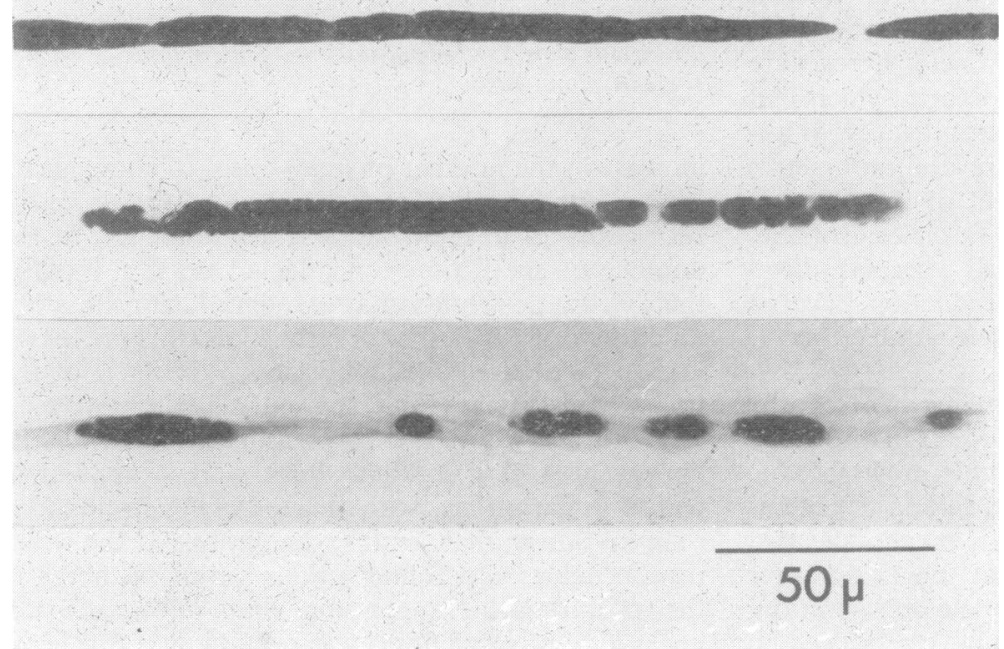

FIG. 5. Different stages of degeneration seen in single fibres from affected median nerves in the mid-forearm (Gps 221, 252, 260). $1 \%$ osmium tetroxide. 


\section{proximal}

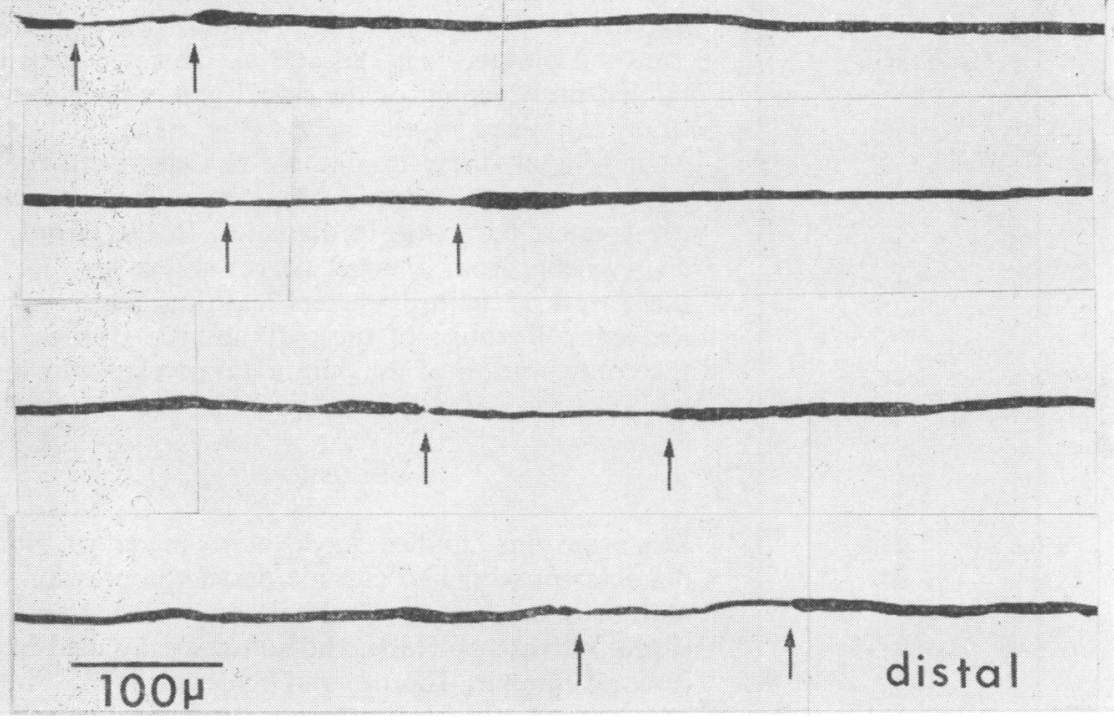

FIG. 6. Gp 260.

Consecutive lengths of a single fibre from the median nerve in the mid-forearm to show intercalated segments occurring at regular intervals along the fibre. $1 \%$ osmium tetroxide.

TABLE 3

GUINEA-PIGS USED TO STUDY RELATION BETWEEN INTERNODAL LENGTH AND DIAMETER

\begin{tabular}{|c|c|c|c|}
\hline Animal & $\begin{array}{c}\text { Age } \\
\text { (months) }\end{array}$ & Nerve & $\begin{array}{c}\text { Muscle response to } \\
\text { nerve stimulation }\end{array}$ \\
\hline $\begin{array}{l}\text { A J } \\
216 \\
221 \\
230 \\
252 \\
254^{*} \\
260^{*}\end{array}$ & $\begin{array}{l}41 \\
22 \\
33 \\
42 \\
24 \\
41 \\
26\end{array}$ & $\begin{array}{l}\mathbf{R} \text { median } \\
\mathbf{L} \text { median } \\
\mathbf{R} \text { median } \\
\mathbf{R} \text { median } \\
\mathbf{L} \text { median } \\
\mathbf{L} \text { median } \\
\mathbf{R} \text { median }\end{array}$ & $\begin{array}{c}\text { Absent } \\
\text { Absent } \\
\text { Delayed } \\
\text { Delayed } \\
\text { Delayed and dispersed } \\
\text { Absent } \\
1 \text { surviving motor unit only }\end{array}$ \\
\hline $\begin{array}{l}244 \\
245\end{array}$ & $\begin{array}{l}8 \\
8\end{array}$ & $\begin{array}{l}\mathbf{L} \text { median } \\
\mathbf{L} \text { median } \\
\mathbf{R} \text { median } \\
\mathbf{R} \text { median }\end{array}$ & $\begin{array}{l}\text { Normal } \\
\text { Normal } \\
\text { Normal }\end{array}$ \\
\hline $\begin{array}{l}246^{*} \\
248^{*}\end{array}$ & $\begin{array}{l}8 \\
8\end{array}$ & $R$ median & $\begin{array}{l}\text { Normal } \\
\text { Normal }\end{array}$ \\
\hline
\end{tabular}

* Radial nerves also used for internodal length/diameter measurements (see Table 5).

TABLE 4

INTERNODAL LENGTH AND DIAMETER IN AFFECTED AND CONTROL MEDIAN NERVES (50 INTERNODAL SEGMENTS MEASURED IN EACH CASE)

\begin{tabular}{|c|c|c|c|c|c|c|}
\hline & \multicolumn{3}{|c|}{ Internodal length $(\mu)$} & \multicolumn{3}{|c|}{ External diameter $(\mu)$} \\
\hline & Range & Mean & S.D. & Range & Mean & S.D. \\
\hline \multirow{2}{*}{$\begin{array}{l}\text { Affected } \\
\text { nerves } \\
\text { Control } \\
\text { nerves }\end{array}$} & $700-800$ & 737 & $27 \cdot 2$ & $3 \cdot 7-10 \cdot 2$ & $6 \cdot 90$ & $1 \cdot 28$ \\
\hline & $700-800$ & 744 & $24 \cdot 8$ & $6 \cdot 6-11 \cdot 5$ & $8 \cdot 64$ & $1 \cdot 35$ \\
\hline
\end{tabular}

in the affected animals could be due to their greater age, since transverse sections in other old guineapigs had already shown normal fibre diameters in fascicles which had escaped compression at the wrist (Fig. 3 and Table 2). However, to make sure that age was not a contributing fartor, radial nerves were taken from young control animals and from old animals with affected median nerves. Single fibres were obtained by teasing, and diameter measurements on 74 segments with a length of 900 to $1,000 \mu$ were made, 40 being from old and 34 from young animals. In all cases, fibres were taken from the radial nerve above the elbow. Details of the animals used are shown in Table 3.

The results are shown in Table 5, and it can be seen that the mean diameter was $10.5 \mu$ for the young animals and $10.0 \mu$ for the old ones; this difference is not significant at the $5 \%$ level $(t=1 \cdot 14 ; P>0.2)$. This makes it very unlikely that the age of the animals contributed to the reduction of fibre diameter which had been found in the case of the median nerve.

In addition to the reduction in diameter, some of the fibres from affected nerves showed other morphological changes which were rarely, if ever, seen in the control median nerves or in the radial nerves of old animals. One such change was irregularity of the contour of the myelin, similar to that seen in the early stages of Wallerian degeneration. This irregularity was particularly common in the region of the nodes of Ranvier (Fig. 8b). Differences could 


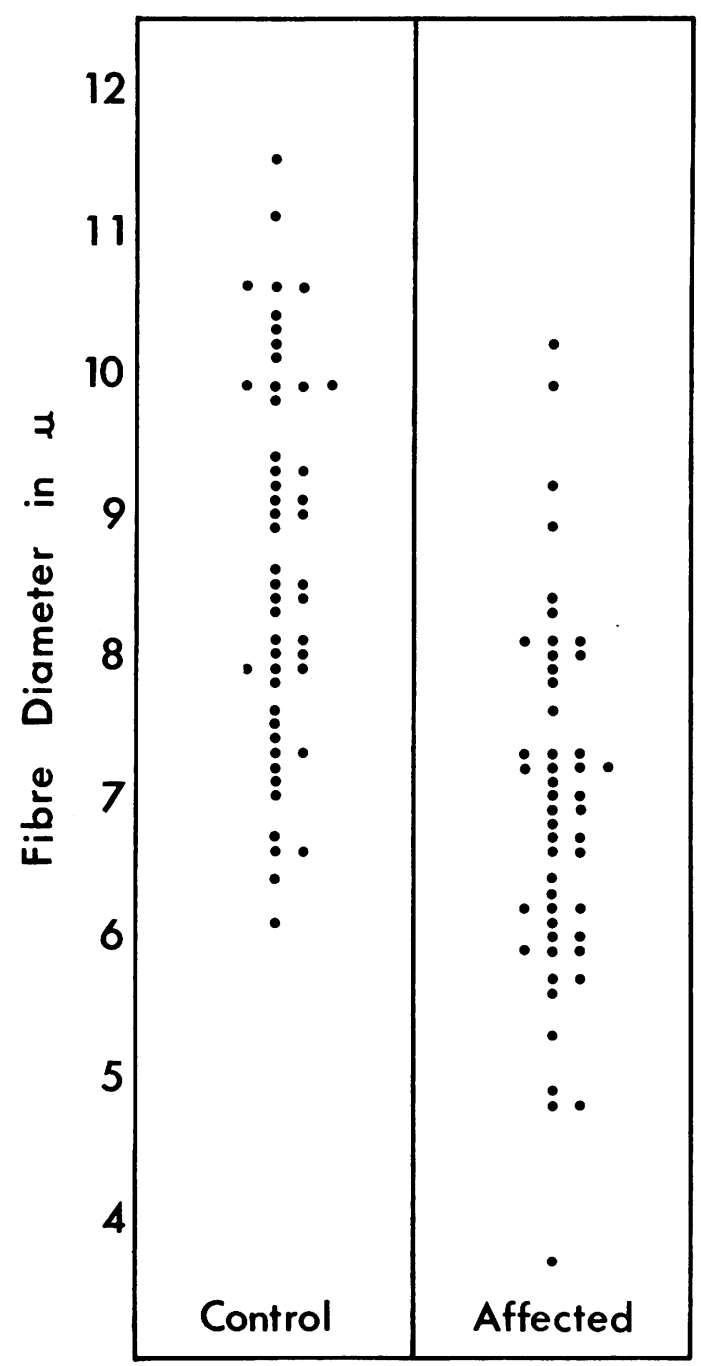

FIG. 7. External diameter of internodal segments 700 to $800 \mu$ in length, from control and affected median nerves in the mid-forearm.

TABLE 5

INTERNODAL LENGTH AND DIAMETER IN RADIAL NERVES OF YOUNG AND OLD ANIMALS

\begin{tabular}{|c|c|c|c|c|c|c|}
\hline & \multicolumn{3}{|c|}{ Internodal length $(\mu)$} & \multicolumn{3}{|c|}{ External diameter $(\mu)$} \\
\hline & Range & Mean & S.D. & Range & Mean & S.D. \\
\hline $\begin{array}{l}\text { Young } \\
\text { animals } \\
\text { ( } 34 \text { internodes) }\end{array}$ & $900-1000$ & 952 & $25 \cdot 2$ & $7 \cdot 4-14 \cdot 1$ & 10.5 & $1 \cdot 64$ \\
\hline $\begin{array}{l}\text { Old animals } \\
\text { (40 internodes) }\end{array}$ & $900-1000$ & 953 & $28 \cdot 6$ & $6 \cdot 1-13 \cdot 4$ & $10 \cdot 0$ & 1.99 \\
\hline
\end{tabular}

also be detected between the regions immediately proximal and distal to the node, the distal side being swollen and rounded (Fig. 8c), whereas the terminaP part of the segment on the proximal side appeared thin and pointed (Fig. 8d and e). This was accompanied by widening of the nodal gap, which somesen times contained myelin debris (Fig. 8f).

In general, these qualitative changes were most marked in those internodal segments which showed the greatest reduction in diameter. In the group of 50 segments from affected nerves shown in Fig. $7 \stackrel{\vec{S}}{\sim}$ there were 12 with diameters less than any seen in the control group; of these 10 showed changes in the configuration of the paranodal myelin or in the width of the nodes themselves.

\section{DISCUSSION}

Few previous studies have been made of fibre $\vec{\omega}$ diameter proximal to chronic nerve compression in man or in experimental animals. In a patient with a carpal tunnel syndrome who subsequently died of a cerebral tumour, Thomas and Fullerton (1963) were $\omega$ able to study the median nerve above, at and below:the level of the lesion at the wrist, and to compareatio with the less affected (but not completely norm(1)을 median nerve of the opposite arm. From thairtransverse sections, histograms of fibre diameterr were constructed, but while these showed marked응 abnormalities at the level of the lesion and distal \&o it, fibre diameter in the forearm was normal. Duncen (1948) found a normal fibre diameter $5 \mathrm{~mm}$ abope $\overrightarrow{\vec{\omega}}$ local demyelination produced by ligatures in young rats and kittens. Weiss and Hiscoe (1948) used $a_{0}$ segment of artery to produce nerve constriction in rats, but as the nerve was also crushed proximal to the level of constriction, their results are not strictlyo relevant to our own. In fact, they found axonal $\frac{\otimes}{\square}$ swelling immediately above the constricted zone, but $\cong$ this did not extend proximally. No reduction in fibre $\overrightarrow{\vec{O}}$ diameter was noted.

In view of these negative findings, it is interesting that one of our animals with a le:ion at the wrist which was mainly demyelinating (Gp 182) showed no reduction in either the number of fibres or in the proportion of large fibres in the forearm. The fibre diameter histogram was also normal. There is thus no direct evidence that compression sufficient to produce demyelination results in a retrograde change $₹$ in fibre diameter. However, in both Thomas ando Fullerton's (1963) patient and in our guinea-pig it is possible that unaffected fibres joining the median nerve in the forearm obscured a slight change in the diameter of affected fibres. To resolve this question o it would probably be necessary to study single fibres $N$ teased from the nerve at the upper level of the lesion, 

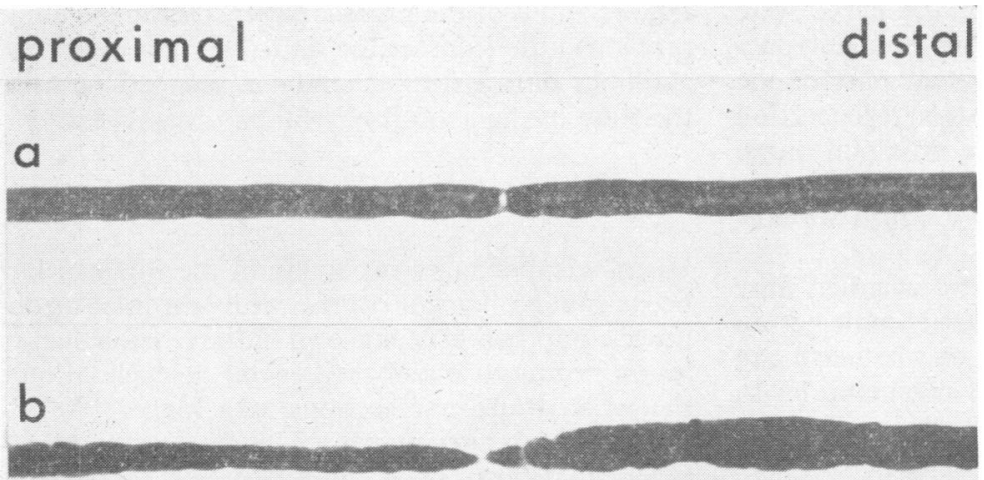

FIG. 8. Nodes of Ranvier from the median nerve in the midforearm: (a) a normal node from a control nerve; (b to f) paranodal changes in fibres from affected nerves. $1 \%$ osmium tetroxide.

C
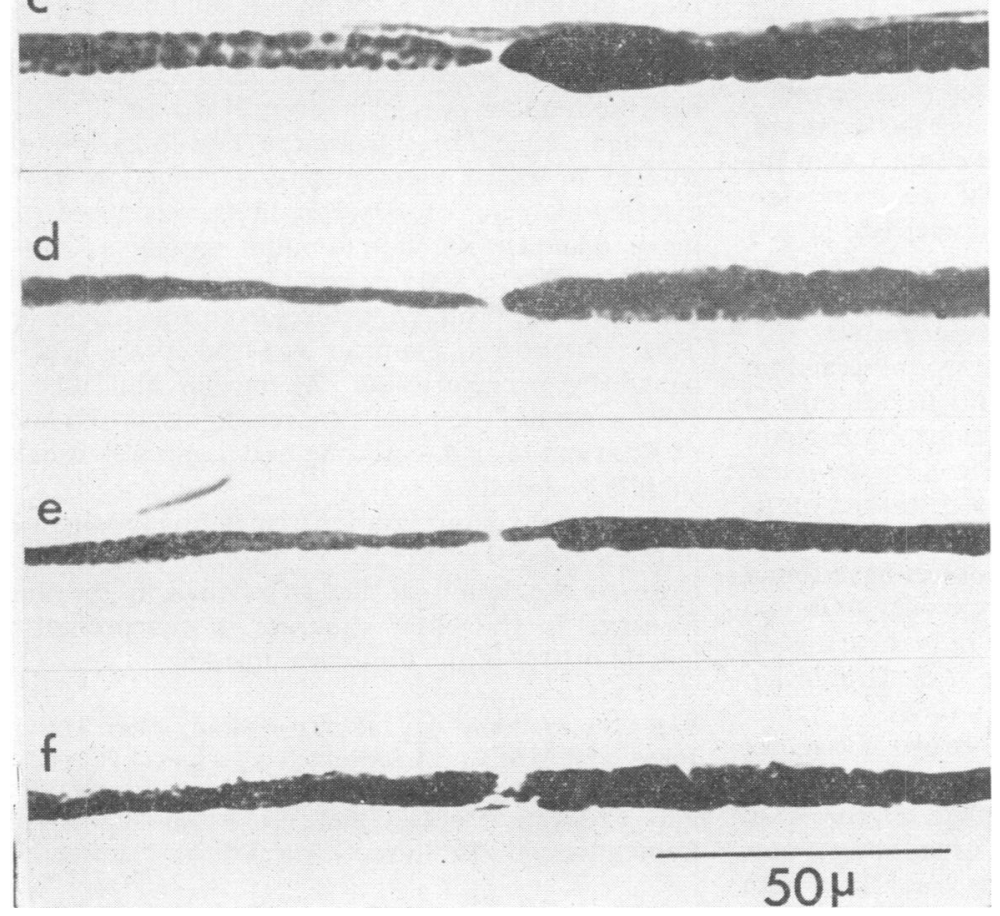

so that in each case one could be confident that the fibre concerned was affected and that it had undergone demyelination and not complete degeneration.

It is clear that once compression is sufficient to produce complete degeneration, marked retrograde changes follow. In two of our animals with complete degeneration at the wrist, the myelinated fibre density in affected fascicles in the forearm had fallen by approximately $40 \%$, the density of the larger ( 6 to $12 \mu$ ) fibres being reduced by 50 to $60 \%$. When similarly affected nerves trom other anımals were teased apart, myelin debris was frequently seen, confirming that retrograde degeneration was taking place. In addition, the diameter of surviving fibres was reduced. When affected and control fibres were matched for internodal length, affected fibres showed a mean reduction in diameter of approximately $20 \%$. This figure may be compared with the reduction in diameter found by Aitken and Thomas (1962) in large myelinated fibres proximal to nerve section in 
the rabbit. When the two ends of the nerve were sutured to allow regeneration, the percentage reduction in fibre diameter in the proximal part of the nerve was only 10 to $15 \%$, but when regeneration was prevented by turning back the proximal stump and avulsing the peripheral stump, the percentage reduction was very close to the $20 \%$ which we ourselves have found.

It would be interesting to know whether fibre degeneration in the forearm necessarily indicates an irreversible change in the neurone, or whether it can be followed by further attempts at regeneration. In view of the retrograde cell loss which is known to follow amputation of a limb (for references see Sunderland, 1968), it would obviously be of considerable interest to extend the present study to cell changes in the spinal cord and dorsal root ganglia of our animals. It should be added that, although we were rarely able to identify regenerating fibres in the forearm, this does not exclude their presence. When studying teased fibres in osmium-stained preparations, regeneration can be recognized with certainty only when maturation of fibre diameter has occurred. Since this depends upon successful contact with the periphery, it is not surprising that we found few regenerating fibres in which the diameter had largely or fully recovered. The possibility that fibres at an earlier stage of regeneration were present in much greater numbers is not excluded by our results.

The qualitative changes which we observed in single fibres deserve some comment. In addition to widening of the nodal gap, we frequently encountered fibres in which the proximal end of the internode was swollen compared with the distal end of the same internode or the distal end of the internode above. This is the reverse of what otbers have found in normal fibres, in which the proximal paranodal region usually has a slightly larger bulbar expansion than that on the distal side of the node (Lubińska, 1954; Williams and Kashef, 1961; 1968).

In our material from the mid-forearm it was not possible to decide for any one fibre whether it had undergone demyelination or complete degeneration at the level of the wrist. However, when fibres closer to the lesion were studied, it was clear that both widening of the nodal gap and an altered configuration of the paranodal myelin could occur without complete degeneration being present distally. For example, Fig. 11 of our previous paper (Fullerton and Gilliatt, 1967) showed a single fibre in which a length of approximately $3 \mathrm{~mm}$ had undergone demyelination at the wrist and was thinly remyelinated. The three internodal segments immediately above this clearly showed bulbous enlargement at the proximal end of each internode, the appearances being similar to the paranodal swellings shown in
Fig. $8 \mathrm{c}$ and $\mathrm{d}$ of the present paper. Osmium staining provides little information as to the nature of these swellings and a further study is planned in which the state of the axon itself will be investigated.

\section{SUMMARY}

Histological changes occurring in the forearm have्य been studied in guina-pigs with chronic median? nerve compression at the level of the wrist. When the lesion produced mainly segmental demyelination af? the wrist, transverse sections at a higher level dip not show a significant change in the total number of myelinated fibres or in the proportion of large dia $-\frac{5}{-}$ meter fibres. However, when the lesion was severe enough to produce complete degeneration at the्s wrist, transverse sections taken in the mid-forearm(15 to $20 \mathrm{~mm}$ above the wrist) showed a marked reduction in the number of myelinated fibres present $\vec{\omega}$ This affected particularly the large fibres (diamete? $6 \mu$ or gieater) which were reduced to approximately half the number present in control nerves.

When single fibres from the mid-forearm werew studied in teased preparations, a reduction in the external diameter of surviving fibres was noted; mean diameter of 50 internodal segments with@ length of 700 to $800 \mu$ was $8.6 \mu$ in control nerves, but only $6.9 \mu$ in surviving fibres from affected nerves This reduction in diameter was sometimes accomn paned by irregularity of the myelin and relatêt enlargement of the paranodal region distal to a noge of Ranvier; in such cases the nodal gap was usura slightly widened.

Paranodal demyelination extending along the internode for 150 to $250 \mu$ was more often seen close to the lesion at the wrist than in the mids forearm. In the latter situation it was present in less than $10 \%$ of the fibres examined.

We wish to thank Mr. K. Yogendran, Miss Maryliro를 Jones, and Miss Carol Aldridge for technical assistance? We also wish to thank the National Fund for Researcl? into Crippling Diseases and the Research Advisory. Committee of the Institute of Neurology for their support

\section{REFERENCES}

Aitken, J. T., and Thomas, P. K. (1962). Retrograde changes in fibre size following nerve section. J. Anat. (Lond.), 96, 121-129.

Duncan, D. (1948). Alterations in the structure of nerves caused by restricting their growth with ligatures. J. Neuropath. exp. Neurol., 7, 261-273.

Fullerton, P. M., and Gilliatt, R. W. (1967). Median and ulnar neuropathy in the guinea-pig. J. Neurol. Neurosurg. Psychiat of 30, 393-402.

Gutmann, E., and Sanders, F. K. (1943). Recovery of fibre numbers and diameters in the regeneration of peripheral nerves. Physiol. (Lond.), 101, 489-518.

Kashef, R. (1966). The Node of Ranvier-A Comparative and Diment sional Study. Ph.D. Thesis: University of London. 
Lubińska, L. (1954). Form of myelinated nerve fibres. Nature (Lond.), $173,867-869$

(1958). 'Intercalated' internodes in nerve fibres. Ibid., 181, 957-958.

(1961). Demyelination and remyelination in the proximal parts of regenerating nerve fibres. J. comp. Neurol., 117, 275-289.

Swallow, M. (1966). Fibre size and content of the anterior tibial nerve of the foot. J. Neurol. Neurosurg. Psychiat., 29, 205-213.

Sunderland, S. (1968). Nerves and Nerve Injuries. Livingstone: Edinburgh and London.
Thomas, P. K., and Fullerton, P. M. (1963). Nerve fibre size in the carpal tunnel syndrome. J. Neurol. Neurosurg. Psychiat., 26, 520-527.

Weiss, P., and Hiscoe, H. B. (1948). Experiments on the mechanism of nerve growth. J. exp. Zool., 107, 315-395.

Williams, P. L., and Kashef, R. (1961). Asymmetry of the node of Ranvier in mammals-an experimental study. J. Anat. (Lond.), 95, 610-611.

Williams, P. L., and Kashef, R. (1968). Asymmetry of the node of Ranvier. J. Cell Sci., 3, 341-356. 